\title{
Sob o signo da diferença
}

Madalena Machado ${ }^{1}$

A literatura que se apresenta ao público nesta segunda década do século XXI é marcada pelo sinal da transformação. Alguns críticos temendo as controvérsias, preferem, os delicados, não nomear o conjunto das produções culturais, formas de pensamento aos quais estamos expostos e que, a forma literária se apropria na busca de sentidos conforme seu sopro vital. Assim, longe de querer o consenso, além do genérico nome de contemporânea, a literatura do nosso tempo (a pós-modernidade) tem nome e sobrenome: pós-moderna. Todavia, tanto seus detratores quanto seus adeptos assumem que não estamos mais no estágio de uma fé irrestrita no futuro porque ele está aí, já chegou há mais de vinte anos; não se pode mais homogeneizar as estruturas do ser, aquilatar as formas de sensibilidade e, isto em forma de arte literária, deve receber um nome com o qual assumimos o risco de sustentar enquanto estética literária ou período literário. Isto posto, porque entendemos que o pesquisador da literatura, muito mais que o fruidor na sua lide diária, se depara com conceitos, generalizações, ponderações enfim, que é preciso desmistificar ou criar conforme o entendimento procurado na produção literária dentro da globalização que nos envolve.

Os textos ficcionais, os poemas e outras formas de expressão do campo literário são cada vez mais acessíveis com o advento da Internet, sobretudo há os que se arrogam a alcunha de autores e clamam por importância em tempos midiáticos de blogs, Orkut,

\footnotetext{
${ }^{1}$ Professora e Pesquisadora na UNEMAT - Campus de Pontes e Lacerda; Credenciada no Programa de Pósgraduação em Estudos Literários (PPGEL) na UNEMAT - Campus de Tangará da Serra. É Graduada em Letras (UNEMAT); Mestre em Estudos Literários (UNESP); Doutora em Teoria Literária (UFRJ); Pós-Doutora em Literatura Brasileira (SORBONNE); Coordenadora do Núcleo de Pesquisa em Literatura "Manoel de Barros"; Líder do Grupo de Pesquisa: Literaturas na Interface entre o clássico e o contemporâneo (CNPq). E-mail: dramadalena@unemat.br
}

Brasiliana - Journal for Brazilian Studies. Vol. 3, n.1 (Jul. 2014). ISSN 2245-4373. 
Twitter, Facebook da vida. Para além destas superficialidades, existem os autores que merecem ser lidos, mas muitas vezes sofrem o preconceito do mercado editorial, dos pseudocríticos que impõe juízos de valor insustentáveis, pois baseados simplesmente no local de nascimento do autor e, o pior dos ostracismos é não terem leitores à altura de seus textos. Muito comum também, no campo da teoria, é a orientação de que a literatura na pós-modernidade é marcada com o sinal da multiplicidade, deslocamentos, as verdades plurais, a presença de paradoxos insolúveis, a metaficção, discussão sobre o que é centro, margem, incluindo e não menos importante a possibilidade de questionar. Sabendo que este último traço distintivo não pode se reduzir à literatura atual, acrescentamos que tal ato na pós-modernidade ganha relevo porque o questionamento é levantado desde a prática. Ao denominarmos este ou aquele texto com a insígnia do período literário que aqui exploramos, temos consciência da inserção no tempo presente, do processo significativo ser mutilado, pois inconcluso. Porém é preciso salientar que, ser cúmplice e distante, registrar e contestar as próprias formulações faz do pós-modernismo e sua vinculação ao presente, uma forma mais afinada de nossa cultura com o que há de mais humano em termos literários.

\section{A diferença em literatura}

Recortemos para este estudo um fator muito apontado teoricamente em textos literários da atualidade: a diferença. Tomemos um autor pertencente ao cânone, sucesso de público e crítica e outro com a mesma qualidade estética, um conjunto de publicações consideráveis, iniciando a ser conhecido pela crítica especializada, mas sem o apelo mercantil ligado ao público. Um poeta, outro prosador, ambos matogrossenses. A distinção se dá pelo distanciamento dos grandes centros, autointitulados determinantes quando se trata de ressaltar o aspecto intelectual, cultural e econômico no Brasil. Manoel 
de Barros (1916) e Ricardo Guilherme Dicke (1936-2008). No poeta, temos eleitos no seu caminho literário, a voz do menino, velho, a prostituta, o andarilho, animais e trastes sem nenhuma utilidade para a sociedade capitalista. No romancista, um personagem chama atenção nos seus mais diversos enredos: o homem que se sobressai a um conjunto social movido pela igualdade nos modos de pensar e ser; ora é um professor de filosofia aposentado, um cigano tocador de viola, ora um místico, o aleijado amante de pintura e literatura, o coveiro cujos pensamentos confrontam um ditador.

No poema "O cisco" do livro Tratado geral das grandezas do ínfimo (2005) já podemos antever o poder desta literatura: “O cisco há de ser sempre aglomerado que se iguala a restos./ Que se iguala a restos a fim de obter a contemplação dos poetas" (p. 11). Temos por esta via a matéria de que se nutre a poesia de Manoel de Barros. Enquanto no livro Toada do Esquecido E Sinfonia Equestre (2006), Ricardo Dicke no primeiro conto, cria uma narrativa povoada de ladrões com a posse do ouro e perdidos pelo caminho da vida. Ali estão presentes homens cujos interiores desconhecem, fugindo da captura aparente, vão ao encontro da morte, não sem antes experimentar a beleza da música/vida que o rádio insiste em lhes sonegar. Só o Cavaleiro e sua persistência no dial atenta para a sonoridade libertadora das agruras pelas quais passam. É preciso destacar que ambos os autores aos prestarem reparo no momento presente, bem ao gosto pós-modernista, mostram uma conscientização aguda de que não é possível observar o todo. Se a epopeia louvava o passado grandioso de um povo, o romance moderno apostava suas fichas no futuro, na otimização do progresso, contudo, a literatura que ora discutimos, preocupa-se com o homem presente e o tempo é agora. Daí o diferente surge à nossa frente sob um olhar mais detido, mais circunstanciado. $\mathrm{O}$ míope nesta observação não é um defeito, é a capacidade de olhar para além das aparências, o cisco, o homem extraído da multidão são, provocam a dialética. 


\section{À luz da teoria, a literatura aninha o diferente}

No encurtamento das distâncias, a lógica invertida em que o grande se torna pequeno e este se encontra ampliado, chegamos às explicações para o que Zygmunt Bauman (1998) alerta a respeito da chegada de um estranho e suas consequências diante de um mundo já conhecido. Segundo ele, "o estranho despedaça a rocha sobre a qual repousa a segurança da vida diária." (1998, p. 19). Logo, já não importam os afazeres rotineiros, a contemplação é o motivo maior de sentir, ocupar um lugar no mundo. Mesmo que para isto venha a sensação inarredável de mal estar, um desconforto gerado pelo descentramento quando as margens começam a se expressar.

Em se tratando do homem, desnorteado por não entender sua presença no mundo, coisa entre coisas, a pequenez vem grafada sob forma de poesia em Retrato do artista quando coisa (2004a): "Vou deixando pedaços de mim no cisco. / O cisco tem agora para mim uma importância/ de Catedral." (p. 23). O que antes contrastava multidão, resíduo, neste instante passa para dentro do ser e espalha efeitos da desimportância. A agudeza na forma acentuadamente reflexiva de vida (a Catedral) dos próprios pensamentos, pode gerar angústia, o desconforto de habitar o próprio corpo ao que testemunha o texto pós-moderno, pois: "privilegia a heterogeneidade e a diferença como forças libertadoras na redefinição do discurso cultural." (Harvey, 2005, p. 19). Sob tais aspectos, não podemos negligenciar esta alteridade que não se impõe mas, se sobressai pela maneira de se portar no instante sem demarcação cronológica. Pura força reflexiva, o homem neste contexto é capaz de notar a peculiaridade que tem o cair dos horizontes, a metamorfose do dia provocando o silêncio, por sua vez indiciador da transformação iminente. É assim com os esquecidos da sorte, rumo ao desconhecido, fugitivos do mundo, mas não do destino que lhes espera pela mão assassina de El Diablo; seguem o rastro daquele companheiro que finge de homem sendo mulher. Descoberta por 
Cavaleiro o qual se apaixona pela algoz, chega até mesmo a lhe apresentar a toada que imprime ritmo ao destino de todos os enredados, esquecidos da "Aldeia global" que a todos sufoca por meio da "universal cumplicidade" (Dicke, 2006, p. 31). Reza a toada um clamor sufocado, quase uma súplica em favor dos "sozinhos, solitários, humilhados, os perdidos (...)" (2006, p. 74) a quem ninguém para a fim de escutar suas dores, os amores não correspondidos, a ausência de um ideal nobre. A dura sequência experimentada no vazio dos campos carbonizados, o sol escaldante tornam-se apenas detalhes perto da aridez das almas sem representação.

Ítalo Calvino (2001) já havia antevisto que a rapidez é uma das propostas a ser consideradas no novo milênio em formato literário. A mutabilidade tanto no contorno humano quanto nas ideias encontradas nos textos literários, provoca um pendor necessário a que nos debrucemos, se quisermos ter mais clareza da literatura nossa de cada dia. Portanto, não se justifica mais falar, ou melhor, buscar o que o texto nos propõe e sim como nos propõe. Da mesma forma que Guimarães Rosa já alertava que o importante não está na partida nem na chegada, mas na travessia; o processo se mostra cada vez mais equipado. Saber como se faz poesia é uma boa pedida nesta argumentação, conforme ensina/poetiza Manoel de Barros nesta parte do livro Matéria de poesia (2001):

\section{(...) As coisas jogadas fora}

têm grande importância

_ como um homem jogado fora

Aliás é também objeto de poesia

saber qual o período médio

que um homem jogado fora

pode permanecer na terra sem nascerem 
em sua boca as raízes da escória

As coisas sem importância são bens de poesia (...)

(Barros, 2001, p. 14-15)

O traste em todos os pormenores vem para a roda de discussão, o "como" a escória expõe seus estertores, afiança sua identidade não possuindo nome, fixidez, subsumida na opressão de dever, ter uma explicação para cada ato, gesto prenunciado. $\mathrm{O}$ algo a mais do qual não se pode passar ao largo, a vida presente, os homens presentes lembrando Drummond - com um pensamento a dialetar, deixam de ser vistos por cima do ombro, com um pré-julgamento, pois já estão diminuídos pelo sistema e isto não cabe mais enfatizar.

No livro Condição Pós-moderna (2005), David Harvey ensina que a irrupção de diversas possibilidades faz do pós-modernismo, a transformação cultural mais condizente com a mudança de sensibilidade que o mundo experimenta. Desta maneira, o leitor é capaz de se identificar aos personagens pós-modernos uma vez que estes, na perspectiva teórica aludida, "parecem confusas acerca do mundo em que estão e de como deveriam agir com relação a ele." (2005, p. 46). Isto porque não há mais referência a seguir, perdeu-se o sentido do caminho reto, o mapa a ser palmilhado se desintegrou fazendo o homem experienciar como em nenhum outro período, o sentido da solidão, o vazio dentro e fora do mundo das ocupações. O bandido de ontem, o louco da estrada de hoje, dão a tonalidade para o que Harvey chama de tratamento da diferença e da alteridade "como algo que deveria estar onipresente desde o início em toda tentativa de apreensão da dialética da mudança social." (2005, p. 320). O estado de exceção ao qual antes do pós-modernismo os habitantes ficcionais eram qualificados por não comporem a ordem, se comportarem de acordo com o previsível, são agora vistos pela normalidade se o debate gira em torno do diferente. Para Harvey "as imagens da decadência" (2005, 
p. 280) compõe o quadro dessa humanidade em busca de maneiras outras de pensar e sentir. Do que extraímos o desnorteio neste fragmento do conto "Toada do Esquecido": “(...) já não sei quanto tempo estamos aqui viajando, o tempo se perdeu atrás duma cortina de semanas, talvez meses, os dias se foram, para onde foram? Ninguém o sabe, e todos fingem que o sabem, (...)” (Dicke, 2006, p. 15).

\section{Mato Grosso, mote literário}

O espaço matogrossense continuamente percorrido pelos habitantes ficcionais dickeanos assim como as personas poéticas barreanas, para longe da disputa teórica de local com universal, denota por outro tanto, a aprendizagem voltada ao humano, conforme vemos expresso em:

Aprendo com abelhas do que com aeroplanos.

É um olhar para baixo que eu nasci tendo.

É um olhar para o ser menor, para o

insignificante que me criei tendo,

O ser que na sociedade é chutado como uma

barata - cresce de importância para o meu

olho.

Ainda não entendi por que herdei esse olhar

para baixo.

Sempre imagino que venha de ancestralidades machucadas.

Fui criado no mato e aprendi a gostar das

coisinhas do chão -

Antes que das coisas celestiais. 
Pessoas pertencidas de abandono me comovem:

tanto quanto as soberbas coisas ínfimas.

(Barros, 2004a, p. 27)

As expressões "olhar para baixo", "ser menor", "insignificante", "coisinhas do chão", "pessoas pertencidas de abandono", "coisas ínfimas", equivalem a nomeação/criação poética para o que foge ao convencional em matéria literária. Ao mesmo tempo em que fica explícita a vontade de lhes fazer falar, ser, perante um contexto impositivo de silêncio. Isto em Barros porque em Dicke, aqueles homens que entre si tem nome: El Diablo, Cavaleiro, Zabud, Gepetto, Elpenor e Palinuro, são obrigados a usar uma máscara durante toda a errância a que se submetem. Mais que disfarce, ela esconde o desconhecido de dentro deles, o não se encontrar no "grande teatro do mundo" como o narrador faz questão de salientar durante toda a narrativa. Viver o problema das máscaras no universo narrativo pontua a vivência do vazio interior, próprio deste artifício e por meio de seu uso, procura suprir mesmo com o que na aparência é absolutamente tão diferente. No que convergem aprendizagem e olhar, o ínfimo, o pequenino alijado do poder, por isto chutado, jogado fora. Por outro tanto é perseguido pela polícia, sobretudo pela gana vingativa de Madame El Sapo, a dona do ouro roubado do garimpo $\mathrm{O}$ esquecido, representante de toda a força repressiva, o poderio econômico que não aceita contestação.

Exercitando o olhar proposto pela contemplação, voltemos a atenção neste momento para o vigor poético deste ser que se move no ritmo proposto pela diferenciação. Assim manifesto no Livro sobre nada (2004b):

Catre-Velho é um traste pessoal à-toa.

Nossa mãe falava: 
Não vale um cabelo.

Não serve nem pra remendo.

Só presta pra cantar e tocar violão.

Catre-Velho ensinava: A voz de um cantador tem que chegar a traste para ter grandezas...

Ele tinha uma voz de harpas destroçadas.

(Barros, 2004b, p. 25)

Não basta saber que catre é um tipo de cama em desuso atualmente e o adjetivo velho complementa perfeitamente o nome deste ente sem serventia, à exceção de cantar e tocar violão, entendidos aqui como sinônimos de vadiagem. Traste e grandeza, quem ensina e quem sabe, quem é diferente ganha voz e se põe no circuito existencial, embora de "harpas destroçadas", é dele a voz com a capacidade de distinguir onde há grandeza digna de apreciação. O ser de circunstância do qual nos ocupamos, o que ousa levantar a voz de sensibilidade, agora distinto no meio da padronização, é capaz de se indignar, por exemplo, na seguinte situação. $O$ cavaleiro pressente o desfecho que a todos aguarda, os homens ao seu redor dormem, só ele medita sobre:

(...) este país, este mundo está cheio de gente desesperada, gente que está procurando a morte e gente que mata - e a gente tem de ser conivente, quer se queira ou não se queira, e se calar no seu silêncio feito de raiva, insatisfação e incomunicabilidade. (Dicke, 2006, p. 47)

Embora em silêncio, o leitor tem acesso a seu modo distinto de pensar, manifestar discordância diante de comportamentos alienados. No bando de renegados, só ele 
percebe o que passa em branco aos demais. A diversidade se manifesta por meio da capacidade de enxergar para além da posse do ouro e o que isto representa, tomadas as devidas proporções; a raiva, insatisfação e incomunicabilidade são contrariadas no momento em que se pode pensar nas suas origens. Algo só possível na trama ficcional com um personagem na contramão do senso comum, o Cavaleiro.

Avancemos na discussão tomando de empréstimo o pensamento teórico de Zygmunt Bauman no livro O mal estar da pós-modernidade (1998), sentimento característico ao destacarmos personagens e seres que se tornam poéticos (criativos) ao se ocuparem de si em nossa pesquisa. Bauman primeiro alerta que tratar da diferença na pós-modernidade não representa nada de novo no desafio pós-moderno ao entendimento, porque isto o mundo pré-moderno e moderno já o faziam à sua maneira. Homens e mulheres destas épocas encontraram maneiras diferentes de lidar com os desafios que seu tempo lhe impunha, dado a multiplicidade com a qual se deparavam muitas vezes. O que o autor nos assegura em contrapartida, no tocante à forma contemporânea da diferença e pluralidade, algo não contemplado nem pela prática prémoderna nem pela prática moderna vem a ser na atualidade, a oportunidade de elaborar ou refazer os próprios conceitos. A contribuição a oferecer se relaciona com "o aspecto novo, caracteristicamente pós-moderno e possivelmente inaudito, da diversidade dos nossos dias é a fraca, lenta e ineficiente institucionalização das diferenças e sua resultante intangibilidade, maleabilidade e curto período de vida." (Bauman, 1998, p. 155). Transitoriedade que entendemos não como um desqualificativo para o diferente, mas a cada modo de pensar e ser pode haver outro com o mesmo pendor a ser apreciado. Caso a angústia, o dessabor possam ser acentuados junto da ansiedade e aflição do mundo pós-moderno, resulta o fato de que a sociedade oferece cada vez mais liberdade individual cobrada com o alto preço da menor segurança, da falta de sentido, "porosidade dos limites, incongruência das sequências, volubilidade da 
lógica e fragilidade das autoridades." (1998, p. 157). Aliás, é preciso frisar que a busca de sentidos se torna irrelevante para este contexto.

O dessemelhante avança, ganha terreno na sua imorredoura irrealização. Inscrever-se num presente contínuo, conforme salienta Bauman, a busca por uma identidade enquanto eixo de estratégia de vida pós-moderna é evitar a fixidez (p. 114). Na mobilidade, a leveza do ser. Na liberdade de escolha, as diferenças sociais pósmodernas se apresentam. Do que pontuamos, considerada sua relevância para o estudo da literatura de nosso século, o pensamento de Zygmunt Bauman nos endossa para o destaque feito com os seres poéticos de Manoel de Barros, bem como personagens singularizados de Ricardo Dicke. Se uma opinião mais restritiva os veem enquanto o refugo do consumismo, estes autores nos mostram o contrário. Personas que ultrapassam ou tentam, o esquecimento do mundo mantendo a quota de sensibilidade exigida pela porção humana que não lhes escapa. Motivo para encontrarmos na boca da assassina, a canção que intitula a trama de "Toada do Esquecido", já presente no enredo do romance O salário dos poetas (2000). Apesar de um pouco extensa, vale a pena transcrevê-la:

\author{
_Mais esquecidos que os mortos, \\ vago sonho, vago vento, \\ onde navegam os portos \\ no país do Esquecimento. \\ Esquecimento esquecido, \\ aqui como emparedado, \\ eternamente olvidado, \\ vago no país do Olvido. \\ Quem me livrará da morte \\ que nos esquece devagar,
}


dentro do mundo da Sorte,

no seu tranquilo viajar?

Saudade quero ser

de alguém - quem não sei - quem será?

Enquanto existir Cuiabá,

enquanto o mundo for viver,

que esquecido não quero mais

minha vida continuar,

esquecimentos eternais

respondam-me: onde vão parar?

Horas de olvido tranquilas:

ossos de dores porosas

embaciadas, lacrimosas,

abstratas, tristes pupilas.

Esquecimento vazio

que vagamente percorre

como um rumoroso rio

a paisagem de quem morre,

mais esquecido que os anos

que se foram no abandono,

felicidades e danos,

amém, dormirei meu sono.

(Dicke, 2006, p. 82-83)

Além do anseio estipulado, o conhecimento e valores a se perpetuar, a música que encanta os personagens da narrativa curta que é a "Toada do Esquecido", também 
destaca as misérias do mundo e os que são atingidos por ela naquele romance. Ao ponto de quem a escuta, fica pensando coisas, esquecidos. Se o canto das sereias ao provocar o esquecimento leva à perdição de toda sorte, a toada marca a cadência paradoxal. Percebemos no movimento da canção a tentativa de resgate deste "país do esquecimento". Resgate que se dá pela via da nomeação, seja dos males, infortúnios, seja na travessia desse rio que consome a todos que não despertam do mundo atingido pelo abandono. É precisamente o enovelar da prece e imprecação que se faz a Toada do Esquecido. Prece pelos encantos traduzidos em forma de poesia extraída da música, imprecação contra tudo que impede seu desfrutar, isto é, o lado negativo do esquecimento grafado em maiúsculo. Para tanto é indispensável o silêncio, postura de quem se entrega à reflexão, para se chegar à transcendência daquilo que a matéria não responde, não cumpre nem realiza os desejos. Sonhos são resgatados, inclusive pela capacidade de realizá-los, daí o fascínio exercido na toada. Sonho de uma vida que não seja preenchida com a ideia da morte iminente, os desarranjos provocados pela ação do homem, cuja memória nesse sentido exerce um papel crucial. Na literatura de Ricardo Guilherme Dicke encontramos os personagens em vias de serem "salvos" pela memória, fugir do esquecimento ao se verem contemplados na Toada do Esquecido.

Vejamos, igualmente, com Manoel de Barros o quanto Bernardo é diferente do mundo que o menino estava acostumado a ver no livro Menino do mato (2010):

Por modo de nossa vivência ponho por caso Bernardo.

Bernardo nem sabia que houvera recebido o privilégio

Do abandono.

Ele fazia parte da natureza como um rio faz, como

Um sapo faz, como o ocaso faz.

E achava uma coisa cândida conversar com as águas, 
Com as árvores, com as rãs.

(Eis um caso que há de perguntar: é preciso estudar Ignorâncias para falar com as águas?)

Ele falava coisinhas seráficas com as águas;

Bernardo morava em seu casebre na beira do rio Moda um ermitão.

De manhã, bem cedo, ele pegava de seu regador e ia Regar o rio.

Regava o rio, regava o rio.

Depois ele falava para nós que os peixes também

Precisam de água para sobreviver.

Perto havia um brejo canoro de rãs.

O rio encostava as margens na sua voz.

Seu olhar dava flor no cisco.

Sua maior alegria era de ver uma garça descoberta no Alto do rio.

Ele queria ser sonhado pelas garças.

Bernardo tinha visões como esta - eu via a manhã Pousada sobre uma lata que nem um passarinho no Abandono de uma casa.

Era uma visão que destampava a natureza de seu olhar.

Bernardo não sabia nem o nome das letras de uma

Palavra.

Mas soletrava rãs melhor que mim.

Pelo som dos gorjeios de uma ave ele sabia sua cor.

A manhã fazia glória sobre ele. 
Quando eu conheci Bernardo o ermo já fazia

Exuberância nele.

(Barros, 2010, p. 452)

Bernardo é neste poema o que vai ocupar o centro das atenções, posto em "caso". Ele é o ser da leveza cuja direção do olhar vai na contramão do prestável, visto ser reconhecido por causa do abandono. Sua integração à natureza é total: como um rio, um sapo, o ocaso - o horizonte transformador - além de ser íntimo das águas, árvores e rãs. Para marcar a solidão que o completa, mora num casebre e tem por ocupação o que ninguém mais faz: regar o rio com uma solenidade reiterada, respeitável a si e aos peixes. Entre rãs e garças, a voz poética cede espaço para que o próprio Bernardo manifeste seus pensamentos: "eu via a manhã/ Pousada sobre uma lata que nem um passarinho no/ Abandono de uma casa." Maneira distinta de falar a linguagem da poesia, porque ver a manhã pousada numa lata dentro do abandono de uma casa é exclusividade para poucos. Só para o diferente que é Bernardo, mesmo iletrado segundo a língua padrão, a cultura oficial, porém é quem sabe se integrar à natureza ouvindo seu dialeto, os rumores que ao ouvido apressado só distingue barulho, para ele representa amanhecer ou anoitecer feito de exuberância, pois parte de si. Se em Dicke a toada do esquecido refrigera a alma daqueles homens ávidos por liberdade, em Barros, esta é plena, advinda da observação da natureza ao ponto do sujeito poético se mesclar a ela. O Cavaleiro que vem a ser o equivalente de sensibilidade no conto dickeano, é o único que percebe a riqueza daquela música, fica indignado com a destruição da paisagem assim como a degradação humana da qual faz parte. Da mesma perspectiva aquele olhar que observa Bernardo, como se fosse o narrador, nos apresenta este ser que do seu ponto de vista tem o privilégio do abandono; sente perplexidade ao se deparar com um sujeito pleno de ignorância falar com as águas, enquanto ensina a um "nós" cultos e cônscios do certo 
e o errado, senso de conveniência, a importância dessa atividade. Conhecer Bernardo resulta àquele ser condutor do olhar judicioso, conhecer mais de si mesmo ao aprender com uma natureza que se transforma.

Em Diferença e repetição (2006), Gilles Deleuze investe no conhecimento do mundo desprovido de fundamento, daquilo que o mundo tenta excluir. A repetição, por exemplo, vista enquanto artefato do humor e ironia, por natureza é transgressão, exceção, marca sempre uma singularidade contra os particulares sob o jugo da lei. Não podemos deixar de interferir ao defender na nossa argumentação, como os seres poéticos e personagens em destaque transgridem a ordem, subvertem o esperado. $\mathrm{O}$ movimento que a tudo desassossega para Deleuze, transmite de sua inquietude a representação de uma esfera ligada aos indiscerníveis (coisa e conceito) quando se discute acerca do "conjunto destes princípios forma a exposição da diferença como diferença conceitual ou o desenvolvimento da representação como mediação" (Deleuze, 2006, p. 33). Já apontávamos antes a respeito de como o olhar nos respectivos contextos indica a mediação do que agora vemos em termos teóricos. Somente compreende a diferença aquele que vê no ato de repetir, a heterogeneidade de uma apresentação. Assim expressa, podemos adiantar que se antes era a representação, alguém se manifestando por, no ato diferencial, o sujeito se apresenta sem rodeios ou interferências. Algo de suma importância em se tratando daquele ser ou situação movida pela inadequação. A diferença que se liga diretamente à determinação tem força autônoma sem o fundo conceitual de analogias e restrições filosóficas. Colocar o problema, ser a questão, são formas muito amiúdes de se declarar a disparidade desta ou daquela maneira de contemplar o que é incomum. O "estatuto do problemático" (p. 180) implica segundo Deleuze, na figura principal levada em conta na discussão do caos = mundo visto pelas coordenadas do sistema literário. O teórico nos afiança acerca do dissimilar que este, ao se erigir como uma questão tem a prerrogativa de captar a 
potência do atordoamento, embriaguez, crueldade e mesmo da morte (p. 366). A ideia chave do livro Diferença e repetição é a busca por definição ao que o autor chama de simulacro, seu sistema afirma a "divergência e o descentramento; a única unidade, a única convergência de todas as séries é um caos informal que compreende todas elas." (2006, p. 384). Do momento em que é o próprio ser quem se diz, instaura-se a diferença, por conseguinte, um intenso jeito de se capturar a sensibilidade muitas vezes ausente num mundo de devir.

\section{Conclusão: o diferente e a abertura ao devir}

Os procedimentos teóricos visualizados em Deleuze nos auxiliam na compreensão de "Sinfonia Equestre" no tocante a apreender a diferença nesta narrativa. A história gira em torno da vingança empreendida por Janis Mohor movida pelo assassinato do pai, Hildebrando Mohor. Casada com Jan ela mantém um estranho casamento permanecendo ambos virgens, ela faz as vezes da donzela guerreira e ele tem medo de tudo até da própria vida. Com a morte do pai, Janis herda as terras e os bens, mas sua razão de viver se concentra na vingança. Ela é acompanhada de perto em todas as suas ações por Belizário, um contador de histórias cujo olhar é apurado para a beleza e a contemplação, além de se mostrar apaixonado por Janis, mantém este sentimento em segredo. Tem sempre um conselho certo na hora adequada, já que viveu muitos anos num monastério; cavalgam sem descanso rumo aos horizontes, Janis aprende com ele a diferença de ser num mundo estruturado pela posse das terras. Tanto assim, que numa das cenas de maior tensão do conto, a personagem empreende uma prece pedindo sagração às águas, doa todos os seus bens e luta até o fim pelo que acredita de mais puro e sagrado no mundo. A sinfonia regida com as patas dos cavalos nas andanças pelas terras disputadas, faz o narrador concluir da narrativa que "o lugar de chegada é muito 
longe, por isso não cabe andar a pé e sim a cavalo, (...)" (Dicke, 2006, p. 153), sendo longe, o que parece importar para todo o enredo é a travessia meada de questões tais como a que Janis se pergunta: "Os homens descem aos abismos ou sobem aos abismos?" (2006, p. 163) os que estão à frente, dentro do homem, intranquilo com os fatos e as pessoas ainda não tocadas com as transformações operadas com a vida. Belizário num primeiro plano e Janis em seguida, depois de se deixar levar pelo aspecto sensível de se enxergar no outro, compõem ambos o ser da diferença, pois a encarnam nesta narrativa de Ricardo Dicke.

Convergindo ao pensamento de Gilles Deleuze quanto à diferença poder ser detectada por meio do questionamento, Jacques Derrida em Escritura e diferença (2005) nos ensina que a aventura do olhar bem como a conversão na maneira de questionar, especifica uma inquietação. A literatura, o homem que a compõe e consome, partem de um vazio, "Esta vacância como situação da literatura é o que a crítica deve reconhecer como a especificidade do seu objeto, em torno da qual sempre se fala." (Derrida, 2005, p. 20) (grifos do autor). O pensamento que se funde com a coisa, a angústia daí proveniente destacam o sentido ou a responsabilidade por este; conforme o que já indicávamos anteriormente a respeito do próprio ser poético e/ou personagem se manifestar na literatura em debate.

A cada gesto inquisidor um ato do devir feito questão. Movimento rumo ao direito à palavra com seu dever de interrogar, instaura-se por esse tanto a ruptura. A liberdade fincada na possibilidade da pergunta mediante a falta, a ausência como suas resultantes encaminham ao lapsus, a inexistência de sentidos quando vem ao caso a questão da diferença. Para Derrida, ao buscar significações o homem envereda na errância que é movimento, é, sobretudo, ir mais longe do que a certeza pacífica e sedentária da lógica. Intensificando a ideia segundo a qual escrever/ser só se torna digno de atenção se estiver situado na diferença, o livro em foco provoca a reflexão ao 
manifestar-se sobre o ser que se anuncia no ilegível, supera qualquer espécie de categoria para além até do próprio nome ao escrever-se. (2005, p. 71). A abertura descrita por Derrida como sinal de compreensão, junto de imagens como abismo ou labirinto é o que explica que pode haver sentido no não-sentido; no confronto de metafísica e ontologia a via da possibilidade da pergunta e, principalmente perguntar sobre tudo equivale a presença sempre atuante da diferença. Experiência que para o francês pode ser perturbadora porque investe com todas as forças contra a violência do conceito, sem dúvida, redutor.

Como propugnado pela pós-modernidade, a ausência de centro, o não-lugar são atributos vivenciados na literatura com maior intensidade e, para o contexto em discussão, é levantado por Jacques Derrida em se tratando de uma problemática universal, para ele:

(...) na ausência de centro ou de origem, tudo se torna discurso com a condição de nos entendermos sobre esta palavra - isto é, sistema no qual o significado central, originário ou transcendental, nunca está absolutamente presente fora de um sistema de diferenças. (Derrida, 2005, p. 232)

As diferenças abordadas relativamente à narrativa de "Sinfonia Equestre", o círculo da vida composto de dias e noites entremeados por uma viagem, desbanca o sentimento primeiro de matar o turco Tariq Muza, assassino de Hildebrando. No meio da travessia, o objetivo aparente sucumbe mediante a aspereza do solo; o percurso em meio ao deserto de dores, sentir todo o esbraseado do sol e mesmo assim contemplar cada grão de areia como se folha fosse, entre árvores e rezas de meditação. Assim, não é mais Janis com sua gana de vingança quem determina o rumo dos acontecimentos, é 
Janis transformada em novo ser sabendo-se pequena parte de um mistério que é preciso desvendar - porque o lugar de chegada é muito longe.

Nosso artigo ao juntar num mesmo espaço inquiridor a literatura brasileira feita em Mato Grosso por Manoel de Barros e Ricardo Dicke, entende ambas as produções literárias como espécime da literatura que, na pós-modernidade são amealhadas por uma pergunta intermitente. A cada poema, prosa, o ser diferente é ressaltado em gestos, falas e atos tão perceptíveis quanto a capacidade do olhar à volta, da percepção do que não se acostuma nem se acomoda na repetição mecânica.

\section{Referências bibliográficas:}

Bauman, Zygmunt. O mal-estar da pós-modernidade. Tradução de Mauro Gama e Claudia Martinelli Gama. Rio de Janeiro: Jorge Zahar ed., 1998

Barros, Manoel de. Matéria de poesia. 4ª ed.: São Paulo, Rio de Janeiro: Record, 2001

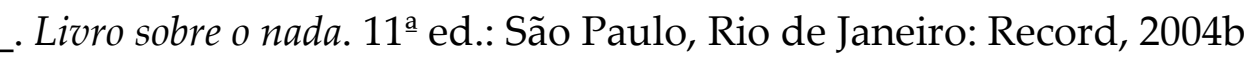

. Tratado geral das grandezas do ínfimo. 03⿳⺈冂大 ed.: São Paulo, Rio de Janeiro: Record, 2005.

. Retrato do artista quando coisa. São Paulo, Rio de Janeiro: Record, 2004a

. Menino do mato. In: Poesia completa. São Paulo: Leya, 2010

Calvino, Ítalo. Seis propostas para o próximo milênio. São Paulo: Companhia das Letras, 2001 
Deleuze, Gilles. Diferença e repetição. Tradução de Luiz Orlandi, Roberto Machado. Rio de Janeiro: Graal, 2aㅡ ed., 2006

Derrida, Jacques. A escritura e a diferença. São Paulo: Perspectiva, 2005

Dicke, Ricardo Guilherme. O salário dos poetas. Cuiabá: Lei estadual de incentivo à cultura, 2000

.Toada do esquecido \& Sinfonia equestre. Cuiabá: Carlini \& Caniato; Cathedral Publicações, 2006

Harvey, David. Condição Pós-moderna. Tradução de Adail Ubirajara Sobral e Maria Stela Gonçalves. São Paulo: Loyola, 2005 